\title{
A Study on Food Service Environments for the Elderly in Community
}

\author{
- Focused on Community Senior Lunch Service \\ 커뮤니티 거주 고령자를 위한 식사서비스 환경에 관한 연구 \\ - 국외의 고령자 식사지원서비스를 중심으로
}

Oh, Eunjin* 오은진 I Park, Haesun** 박혜선

\begin{abstract}
Purpose: Healthy and balanced meal is very important for the elderly to maintain the quality of life in community. Senior meal delivery system and congregate meal services have been played an important role to prevent premature institutionalization of the elderly. Food delivery system and lunch service spaces for the Korean elderly were mostly focused and limited on low-income family. The purpose of this study is to analyze community food services environments for the elderly in the UK, the U.S. and Japan for the possibility of applying those service spaces to Korean community. Methods: Lunch service spaces of these three countries were investigated by literature research and visiting of venues. Pilot study of the elderly meal services in Seoul was done for comparing environments and future research. Results: Lunch service spaces in three countries were mostly community based for accessibility and the types of management were various for the elderly to choose the most suitable services for them. The group dining spaces are usually small and designed to give de-institutional atmosphere. Implications: Food service environments for the elderly in Korea should develop more community based model of food delivery and congregate meal service spaces as well as more de-institutionalized design of those spaces.
\end{abstract}

Keywords Elderly food service space, Elderly congregate meal service space, Community kitchen, De-institionalization of elderly dining spaces

주 제 어 고령자 식사지원서비스 공간, 경로식당 공간, 시니어 런치클럽, 커뮤니티키친, 고령자 식사공간 탈시설화

\section{Introduction}

\subsection{Background and Objective}

60세 이상의 고령자는 정신건강과 면역력 증강을 위하여 건강한 식생활을 하는 것이 매우 중요하다. 최근의 복지정책 이 질병이 발병한 이후의 고령자에 대한 케어보다 예방적인 케어를 중요하게 생각하고 있기 때문에 특히 식사와 관련한

* Director, Ph.D., Gnaymas Consultant, Visiting Professor, College of Architecture, Hongik University (Primary author: oh.eunjin@ gmail.com)

** Member, Professor, Ph.D., Department of Architecture, Inha Technical College (Corresponding author: hanulmadang@ naver.com)
다양한 이슈들이 연구되고 있다(Anne Dillon Roberts et al, The Caroline Walker Trust, 2004).1)

Aging in Place개념에 의한 커뮤니티케어의 중요성이 부각 되면서 고령자의 식사관리는 기하급수적으로 늘어나는 복지 비용을 절감하는 방법의 하나로 매우 중요하게 관심을 받고 있으며, 국외에서는 다양한 식사관련 서비스가 고령자들에게 제공되고 있다. 에너지 레벨을 높이고 만성질환자들의 건강유 지 뿐 아니라 우울증을 예방하는 정서적 밸런스를 위해서도

1) The Caroline Walker Trust는 1988년에 결성된 단체로 노인 건강 과 관련된 각 분야의 전문가 그룹(Expert Working Group)의 연 구결과에 따라 노인영양에 관한 실용적인 가이드라인을 제시하 고 있다. 
고령자는 건강한 식사패턴을 유지하여야 한다. 그러나 혼자 식사하는 노인들은 탄수화물 위주의 간편식을 선호하다 보니 단백질과 섬유질, 수분의 섭취가 매우 부족하며, 위생을 유지 하는데도 많은 어려움이 따른다. 따라서 독거노인에게는 영양 결핍뿐 아니라 식중독 등 음식관련 사고가 빈번히 발생하고 있다.

고령화가 먼저 진행된 국가들은 고령자들에게 신선하고 다 양한 음식을 섭취할 것과 함께 하루 한 끼 이상은 혼자서 식 사하지 않을 것을 적극적으로 권장하고 있다. 이를 위해 어울 려 식사하기 위한, 커뮤니티 내에 공동으로 이용할 수 있는 공 간의 중요성이 부각되고 있다. 다양한 형태의 런치클럽, 시니 어런치 살롱 등 커뮤니티 내에서 건강한 식사를 나눌 수 있는 '커뮤니티 키친(Community Kitchen)'에 대한 관심도 높아지 고 있다(Hwang, Ji Hye et. al, 2010).2)

일본의 전국 커뮤니티카페 네트워크에서는 커뮤니티키친 또는 카페를 다음과 같이 정의하고 있다. 지역사회 안에서 「모이는 곳(たまり場)」，「머무는 곳(居場所)」이 되는 장소 의 통칭으로, (1)사람과 사람이 교차하는 자유로운 공간 (2)모 든 정보의 교차점 (3)친구를 만드는(인적네트워크를 넓히는) 장소 (4)더욱 멋진 삶에 도전하는 계기를 갖는 장소 라고 하였 다(http://blog.canpan.info/com-cafe/profile). 커뮤니티 내에 이러한 공간을 제공함으로 고령자들의 소외감과 우울증을 예 방하는 효과를 가져 올 수 있다고 소개하고 있다.

국내에서는 저소득 고령자를 위주로 식사배달서비스와 경 로식당을 운영하고 있지만, 일반 고령자에 대한 서비스는 매 우 한정되어 있다. 국외의 경우 저소득 고령자만이 아니라 일 반 고령자도 건강상태 또는 수발자의 부재로 인한 식사지원 서비스의 필요성이 크다는 것을 인식하고, 서비스 대상을 폭 넓게 지원하고 있다. 국내에서도 고령화가 심화되면서 일반 고령자에 대한 식사서비스도 그 요구가 점점 증대되고 있고, 유료 경로식당 이용자의 비율도 높으므로 일반 고령자를 고 려한 식사지원 공간에 대한 요구도 높아지고 있다.

또한 국내 경로식당의 공간 구성은 단 시간에 너무 많은 인원에게 식사를 제공하고 있으며, 대부분 고령자만을 대상 으로 하기보다는 복지관의 직원 식당과 겸해서 운영을 하고 있기 때문에, 고령자의 심리적인 상태를 고려한 식사환경으 로 디자인되었다고 할 수 없다. 기존 경로식당 공간의 고령 이용자의 심리를 고려한 디자인 및 가구배치에 대한 연구와 커뮤니티 내에서 접근을 용이하게 하는 필요성이 증대되고 있다.

본 연구의 목적은 국외에서 시행되고 있는 고령자들을 위 한 식사지원서비스 프로그램인 식사배달서비스(wheels on meals)와 회합식사서비스(congregate meals)의 운영과 환경 에 대해서 조사, 분석하여 국내 커뮤니티 내에 거주하는 고령 자들을 위한 식사지원서비스 및 공간에 적용 가능한 기초자 료를 제공하고자 한다. 특히 국외의 런치클럽과 같은 회합식 사 공간의 연구를 통하여, 국내 경로식당의 건축환경 디자인 의 문제점에 대해 파악하고, 커뮤니티 내 소규모 고령자 식사 지원센터의 역할을 할 수 있는 커뮤니티키친의 설치 가능성 에 대해 연구하고자 한다.

\subsection{Methods of Research}

커뮤니티 거주 고령자의 식사공간에 대한 연구를 위하여 커뮤니티케어가 발전한 국외사례를 문헌자료와 방문조사를 통하여 분석하였다. 국외사례로는 영국의 대도시와 농촌지역 의 시니어 런치클럽, 미국의 시니어런치 공간, 일본의 시니어 살롱 등 고령화가 먼저 진행된 국가들에서 시행되고 있는 고 령자를 위한 식사지원서비스 및 공간에 대해 분석하였다. 이 를 통해 기존 국내에서 시행되고 있지 않은 이러한 프로그램 을 반영할 시에 필요한 정책 및 공간계획 시 고려하여야 할 사항 등에 대해 정리하였다.

커뮤니티 내 고령자를 위한 소규모 식사서비스 공간의 국 내 도입가능성을 타진하기 위한 예비조사로, 기존 복지관에서 시행하고 있는 경로식당의 운영현황과 공간에 대한 조사를 실시하였다. 국내 경로식당에 대한 건축계획적인 연구 및 커 뮤니티 내 고령자를 위한 식사서비스 공간에 대한 연구는 현 재 매우 미비한 상태로, 국외 조사를 중심으로 한 비교분석을 통해 국내의 고령자 식사서비스 환경에 대한 문제점을 밝히 고 후속연구를 위한 과제를 제시하고자 한다.

\section{Lunch Senvice Programs for the Elderly in Community}

영국에서 시행되고 있는 식사지원서비스의 유형은 더운 음 식(hot meals), 냉동 음식(frozen meal)을 가정에 배달하는 식 사배달서비스, 고령자들이 모여서 식사하는 런치클럽(lunch clubs), 음식물 구매지원서비스(shopping services), 퍼스널케 어서비스에 포함되는 식사준비 보조서비스 등, 4 개 유형으로 요약할 수 있다. 초기에는 배달서비스 위주로 사업이 진행되 어 왔으나, 최근에는 고령자들의 정신적인 건강도 고려하여 모여서 식사할 수 있는 공간에 대한 관심이 높아지고 있으며, 다양한 형태의 런치클럽이 운영되고 있다. 다음은 대표적인 식사지원서비스인 식사배달서비스와 회합식사서비스의 운영 현황과 공간에 대한 내용이다.

2) 커뮤니티 키친은 안전한 먹거리의 확보와 커뮤니티 내 거주자간 의 교류를 활성화하는데 매우 좋은 효과가 있어, 많은 국가에서 다양한 형태로 설치 운영되고 있다. 


\section{2-1 Meal Delivery Service programs for the Elderly}

커뮤니티에 거주하는 고령자들을 위한 식사배달서비스 는 1939년 영국에서 "Meals on Wheels"라는 프로그램으로 시작 되어 현재는 많은 국가에서 시행되고 있는 식사지원서비스로, 지역에 따라 명칭은 다양하게 쓰이고 있지만 프로그램의 내 용은 유사하다(Yang, Il-Sun, Jung, Hyun_Young, 2003).3) 국 내의 식사배달서비스는 주로 저소득 독거노인 위주로 운영되 고 있지만, 국외의 경우에는 식사배달서비스의 필요성에 대한 평가 절차를 거쳐, 모든 고령자가 혜택을 받을 수 있도록 되어 있다. 저소득 노인에게는 무료로 제공되고 일반 노인들에게도 저렴한 가격으로 식사배달이 가능하도록 되어 있다.

영국의 저소득 고령자들은 무료로 식사배달서비스를 제공 받고 있고, 일반 고령자들도 건강상의 문제가 있을 경우 서비 스를 받을 수 있다. 더운 음식(hot meals)은 1.23 3.42파운드, 냉동음식은 2 3파운드의 가격, 즉 2,000 원에서 5,000 원 정도 의 비용으로 질 좋은 식사를 제공받을 수 있어 고령자에게 높 은 만족도를 보이고 있다(Community Food and Health(Scotland), 2011).4)

미국의 식사배달서비스도 필요한 모든 고령자들에게 서비 스가 가능하도록 되어 있으며, 저소득 노인들은 무료로, 일반 노인들은 식사 가격에 해당하는 금액을 기부하는 형태로 서 비스를 제공받고 있다(http://www.mowaa.org/).5)

국내에서도 식사배달서비스를 1999년부터 공식적으로 정 부의 재정지원을 받아 시행하고 있으나 주로 저소득의 거동 이 불편한 노인만을 대상으로 하고 있어 일반 고령자들이 이 용할 수 있는 기회는 극히 제한되어 있다(Yang, Il-Sun et al., 2003: 736-743).6)

\section{2-2 Congregate Meal Programs for the Elderly}

고령자들을 위한 식사서비스 가운데 회합식사서비스 (congregate meal programs)는 오래 전부터 시행되어온 제 도이지만, 최근 건강한 식생활이 고령자들이 커뮤니티에서 계 속 거주할 수 있는(Aging in Place) 매우 중요한 요소이며, 질 병에 대한 예방적 효과가 크다는 연구결과가 많아지면서 더 관심을 받고 있는 프로그램이다(Yang, Ji Won et al., 2008). 외출이 가능한 노인들이 사회적인 교류를 계속 이어갈 수 있 도록 여러 가지 프로그램들이 시행되고 있는데, 그중에서도

3) Meals on Wheels는 영국, 미국, 호주, 캐나다 등의 국가에서 활 발히 진행되고 있는 고령자 식사지원 프로그램이다.

4) 고령자가 커뮤니티에서 건강과 기능을 유지하기 위해서, 고령자 가 원하는 식사 형태로 선택 가능한 프로그램을 운영하고 있다.

5) 서비스 제공은 건강 상태를 우선적으로 고려하여 제공하며, 경제 적인 조건은 저소득, 일반 구분 없이 제공된다.(Meals on Wheels Association of America)

6) 국내의 식사배달서비스는 복지관의 경로식당을 중심으로 저소득 독거노인 위주로 제공되고 있다.
식사를 위한 정기적인 외출을 하는 것이 매우 중요하기 때문 에 회합식사서비스는 고령자들에게 많은 호응을 받고 있다. 이러한 회합식사공간의 환경은 기존의 단체급식 환경과 같 이 대규모의 공간에서 빠른 시간 안에 배고픔만 해결하는 것 이 아니라. 고령자들이 친근한 사람들과 편안한 환경에서 의 미 있는 교류의 시간을 가지면서 식사할 수 있도록 고려되어 야 한다(Linda Netterville et al, 2013).7)

국내의 고령자를 위한 회합식사는 주로 경로식당이라는 이 름으로 노인복지관에서 제공되고 있는데, 형태가 단체급식 공 간으로 이루어져 있고, 많은 이용자가 짧은 시간 안에 이용하 고 있다. 따라서 기존의 경로식당은 고령자 간에 단지 식사 이 상의 의미 있는 교류를 나눌 수 있는 공간의 역할은 하지 못 하고 있다.

\section{Senior Lunch Service Spaces in the UK, the US, and Japan}

\subsection{Senior Lunch Clubs in the UK}

영국 회합식사의 명칭은 주로 런치클럽이라 불리고 있는데 그 운영 형태는 6 가지 유형으로 분류될 수 있다. 즉, 지방정부, 자원봉사단체, 지역커뮤니티, 관심단체, 커뮤니티카페, 기타 민간단체 등이 운영주체인 형태이다.

(1) 지방정부가 운영하는 유형은 지방자치단체들의 지원을 받아 운영하는 시설로, 커뮤니티센터나 지자체 건물에 설치하 여 운영되고 있다. 식사는 현장에서 조리하는 경우와 외부에 서 조리한 음식을 제공하는 형식이 있으며, 고령자들을 위한 차량 제공도 하고 있다. 초기에는 이러한 유형이 많았으나 점 차 지원상의 문제로 제한이 되고 있다.

(2) 자원봉사단체 운영의 대표적인 모델은 교회에서 제공 하는 것과 노인보호주택(Sheltered Housing)에서 제공하는 것이다. 이러한 클럽들도 정부의 보조를 받는 경우가 많이 있 다. 직원의 구성은 일반 급여를 받는 직원과 자원봉사자들도 이루어져 있다.

(3) 커뮤니티 자치모델은 주로 커뮤니티에서 런치클럽의 운영을 위해 구성된 것으로 대부분 자원봉사자 위주로 운영 이 되고 있으며, 고령자들이 자치적으로 운영하고 있는 곳도 많다.

(4) 관심단체 운영모델은 주로 다문화적 배경을 가진 주민 들이 많이 사는 곳에서 이루어지고 있으며, 영국의 경우 동남 아와 중동 등 여러 지역의 이주민들이 많아 문화적 특성을 가 진 런치클럽의 운영도 활발히 이루어지고 있다. 이러한 클럽

7) N4A(The National Association of Area Agencies on Aging) Conference Presentations에서 발표된 내용으로, 이 단체는 커뮤 니티에 거주하고 있는 고령자들에 대한 서비스와 관련된 여러 이슈에 대해 연구하고 있다. 
들은 서비스지역이 일반 런치클럽에 비해 넓은 지역을 대상 으로 하는 경우가 많다.

(5) 커뮤니티카페에서 제공하는 프로그램들은 고령자를 위 한 식사가격의 할인과 더불어 카페를 중심으로 런치클럽을 운영하는 유형이다. 식당에서 직접 식사를 할 수 있거나 인근 지역에 있는 커뮤니티센터에서 음식을 제공하는 형태로 운영 하고 있다.

Stirling의 Cowane 아트센터에 위치한 The Sunlite Cafe는 지역에 건강한 식사를 제공하고 있는 카페로 유명한데, 주변 에 거주하는 고령자들을 위해 저렴한 가격으로 런치클럽을 운영하고 있다. 이용하는 노인들의 평균 연령은 85 세로 봉사 자와 같이 오는 경우도 많이 있다고 한다. 식당에서 제공되는 식사 외에도 가정에 가져갈 수 있는 과일이나 간단한 식재료 도 판매하고 있다.
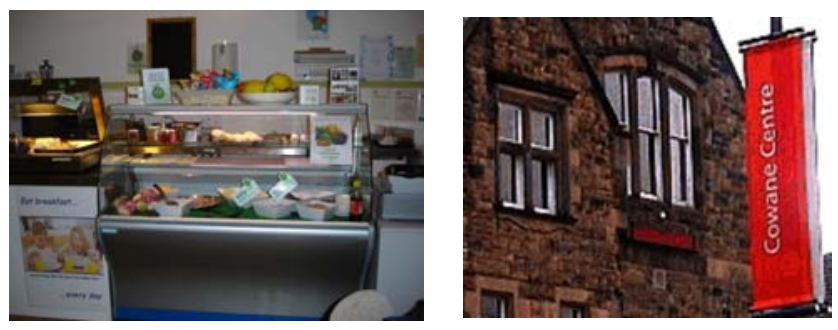

[Figure 1] The Sunlite community Cafe at Cowane Center, Stirling (http://www.stirling.co.uk/arts/cowane.htm)

(6) 민간단체에서 운영하는 유형은 주로 공공 서비스센터 가 적은 농촌지역에서 많이 이루어지고 있으며, 지역의 식당 이나 카페에서 주문을 받아 운영하고 있다(Community Food and Health(Scotland), 2011).

6가지 모델 모두 커뮤니티 밀착형으로 운영되고 있으며, 고 령자들의 접근성을 고려하여 보행이 가능한 거리에 있거나 그렇지 않은 경우에는 차량지원서비스가 대부분 제공되고 있 다. 또한 회합의 규모도 소규모로 운영되어 고령자들이 보다 가족적인 분위기에서 편안하게 식사를 하고, 의미 있는 사회 적 교류를 할 수 있도록 배려하고 있다.

1) Lunch Clubs in Tower Hamlets

런던의 타워햄릿(Tower Hamlets)8)은 2011년 기준인구 254,096 명 규모의 지역으로 아시아 이민자가 많은 곳이다. 백 인이 $45 \%$ 정도이고 그 이외에는 다민족 인구가 거주하고 있 으며 특히 방글라데시(Bangladeshis)와 소말리아(Somalis) 이 주자가 $40 \%$ 가 넘는 지역이다. 이러한 지역적 특성상 다문화 주민을 위한 런치클럽서비스가 많이 제공되고 있다.

8) 타워햄릿(Tower Hamlets)은 32개의 자치구(Borough)와 시티오 브런던(City of London)으로 이루어진 런던광역시(Greater London)에 포함되는 자치구 중 하나이다.
현재 타워햄릿 지역에는 16 개소의 런치클럽이 운영되고 있 으며 많은 수의 런치클럽이 이용자의 문화적인 특성을 고려 하여 서비스가 제공되고 있다. 인구비율로 볼 때 전체 거주인 구 15,000 명당 1 개소의 런치클럽이 운영되고 있다.

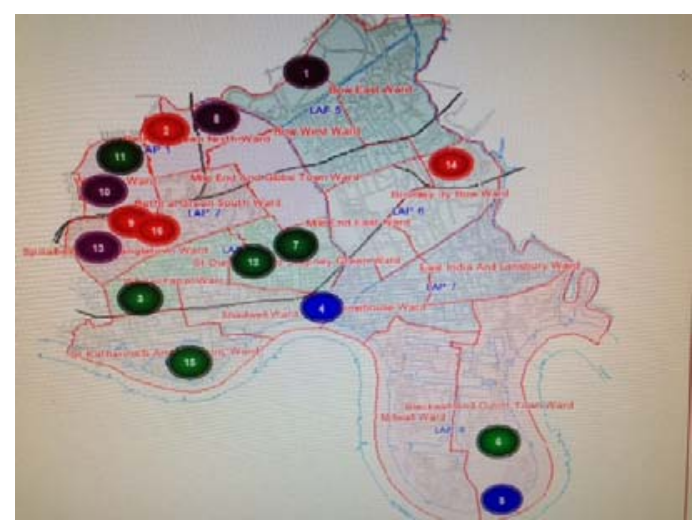

[Figure 2] Tower Hamlets Area Lunch Club Allocation (http://www.towerhamlets.gov.uk)

런치클럽의 운영은 매우 다양한 형태로 이루어지고 있으 며, 매일 서비스를 제공하는 형태와 일주일에 2-3회 제공하는 형태가 있다. 운영시간도 점심만 제공하여 2-3시간만 운영하 는 형태도 있고, 아침을 제공하여 8 시부터 오픈하는 경우가 있으나, 대부분 10 시 이후에 오픈하여 4 시까지 서비스를 제공 하고 있다.

런치클럽의 일일 평균 운영시간은 4-5시간이다. 대부분 건 강과 관계된 프로그램에 집중되어 있으며, 건강에 대한 상담 및 토의, 간단한 운동프로그램, 댄싱, 아트 클래스와 다문화 이주민을 위한 신문읽기나 언어교육 클래스도 제공하고 있다. 일반 복지관의 프로그램보다 담화 형태의 비공식적 프로그램 이 많은 것이 특징이다(London Borough of Tower Hamlets, 2013).

2) Lunch Clubs in Cheltenham, Gloucestershire

영국의 서남부에 위치한 글로스터셔(Gloucestershire)9) 지 방의 첼트넘은 2010년 기준인구 115,300명의 농촌지역으로, 거주인구의 $90 \%$ 이상이 백인이며 스파와 다양한 문화 페스 티벌로 유명한 곳이다. 2013년 기준 24개의 런치클럽이 운영 되고 있어 인구 5,000 명당 1 개소가 설치· 운영되고 있다. 도시 지역에 비해 인구 밀도가 낮고 지역이 상대적으로 넓기 때문 에 도시지역보다 더 많은 수의 런치클럽서비스가 제공되고 있다.

다문화인구로 구성된 타워햄릿 지역과는 달리 이곳은 주로 백인들로만 이루어져 있어, 문화적인 배경에 따른 형태보다

9) 글로스터셔(Gloucestershire)는 영국 잉글랜드(England)의 48개 카 운티(County, 지방정부, Greater London도 카운티 중 하나) 중 하나이다. 
[Table 1] Lunch Club Service Spaces in London Borough of Tower Hamlets

\begin{tabular}{|c|c|c|c|c|}
\hline 구분 & 시설명 & $\begin{array}{l}\text { 운영 및 } \\
\text { 부설형태 }\end{array}$ & 이용인원 & 프로그램 \\
\hline \multirow{4}{*}{ 일반 } & Appian Court & Age Concern & \begin{tabular}{|l|} 
100/day \\
500/week \\
\end{tabular} & $\begin{array}{l}\text { 아트, 운동, } \\
\text { 댄스,게임 } \\
\end{array}$ \\
\hline & $\begin{array}{l}\text { St. James the } \\
\text { Less Luncheon } \\
\text { Club }\end{array}$ & RADICLE & $\begin{array}{l}\text { 25/day } \\
125 / \text { week }\end{array}$ & 서비스연계 \\
\hline & \begin{tabular}{|l|} 
St. \\
Hilda's-Pensioner' \\
s Project
\end{tabular} & $\begin{array}{l}\text { Community } \\
\text { Center }\end{array}$ & $\begin{array}{l}\text { 25/day } \\
100 / \text { week }\end{array}$ & $\begin{array}{l}\text { 비정기적 활동 } \\
\text { 아트, 운동, } \\
\text { 게임, 댄싱 }\end{array}$ \\
\hline & $\begin{array}{l}\text { Toynbee Hall } \\
\text { Older People's } \\
\text { Lunch Club } \\
\end{array}$ & NPO & $\begin{array}{l}\text { 40/day } \\
\text { 240/week }\end{array}$ & $\begin{array}{l}\text { 댄싱, } \\
\text { 아트 „쇼핑 }\end{array}$ \\
\hline \multirow{10}{*}{$\begin{array}{l}\text { 다 } \\
\text { 문 } \\
\text { 화 } \\
\text { 주 } \\
\text { 민 }\end{array}$} & $\begin{array}{l}\text { Harkness Lunch } \\
\text { Club }\end{array}$ & $\begin{array}{l}\text { Children } \\
\text { Education } \\
\text { Group }\end{array}$ & $\begin{array}{l}\text { 30/day } \\
\text { 90/week }\end{array}$ & $\begin{array}{l}\text { 건강상담, } \\
\text { 종교그룹토의 }\end{array}$ \\
\hline & $\begin{array}{l}\text { Island Bengali } \\
\text { Welfare } \\
\text { Organization } \\
\end{array}$ & NPO & $\begin{array}{l}\text { 15/day } \\
\text { 45/week }\end{array}$ & $\begin{array}{l}\text { 건강상담, 운동, } \\
\text { 게임 }\end{array}$ \\
\hline & $\begin{array}{l}\text { Shahjalal } \\
\text { Community } \\
\text { Center }\end{array}$ & $\begin{array}{l}\text { Community } \\
\text { Center }\end{array}$ & $\begin{array}{l}\text { 30/day } \\
\text { 90/week }\end{array}$ & \begin{tabular}{|l|} 
건강상담, \\
종교그룹토의 \\
안과진료
\end{tabular} \\
\hline & $\begin{array}{l}\text { St.Peter's } \\
\text { Luncheon Club }\end{array}$ & $\begin{array}{l}\text { Community } \\
\text { Center }\end{array}$ & $\begin{array}{l}\text { 35/day } \\
\text { 70/week }\end{array}$ & $\begin{array}{l}\text { 에어로빅, } \\
\text { 테라피 }\end{array}$ \\
\hline & $\begin{array}{l}\text { Stifford Older } \\
\text { People Lunch } \\
\text { Club } \\
\end{array}$ & $\begin{array}{l}\text { Community } \\
\text { Center }\end{array}$ & $\begin{array}{l}\text { 25/day } \\
75 / \text { week }\end{array}$ & $\begin{array}{l}\text { 신문읽기, } \\
\text { 그룹토의 }\end{array}$ \\
\hline & \begin{tabular}{|l} 
Wapping \\
Bangladesh \\
Association \\
\end{tabular} & $\begin{array}{l}\text { Wapping } \\
\text { Youth Club }\end{array}$ & $\begin{array}{l}\text { 20/day } \\
60 / \text { week }\end{array}$ & $\begin{array}{l}\text { 신문읽기, } \\
\text { 그룹토의 }\end{array}$ \\
\hline & $\begin{array}{l}\text { Black Woman's } \\
\text { Health and } \\
\text { Family Support }\end{array}$ & $\begin{array}{l}\text { BWHAFS } \\
\text { NPO }\end{array}$ & $\begin{array}{l}\text { 22/day } \\
\text { 44/week }\end{array}$ & $\begin{array}{l}\text { 건강상담, 운동, } \\
\text { 게임 }\end{array}$ \\
\hline & $\begin{array}{l}\text { Somali Senior } \\
\text { Citizen's Club }\end{array}$ & $\begin{array}{l}\text { Somali } \\
\text { Seamen } \\
\text { Granby Hall }\end{array}$ & $\begin{array}{l}\text { 40/day } \\
\text { 200/week }\end{array}$ & 건강상담 \\
\hline & $\begin{array}{l}\text { Wadjir Somali } \\
\text { Community }\end{array}$ & \begin{tabular}{|l|} 
Charity \\
Organization
\end{tabular} & $\begin{array}{l}\text { 20/day } \\
\text { 60/week }\end{array}$ & $\begin{array}{l}\text { 신문읽기그룹 } \\
\text { 토의,컴퓨터 }\end{array}$ \\
\hline & $\begin{array}{l}\text { Women's health } \\
\text { and family } \\
\text { services }\end{array}$ & $\begin{array}{l}\text { community } \\
\text { Center }\end{array}$ & $\begin{array}{l}\text { 30/day } \\
\text { 30/week }\end{array}$ & $\begin{array}{l}\text { 건강강좌 } \\
\text { 아랍어 }\end{array}$ \\
\hline \multirow[b]{2}{*}{ 기타 } & $\begin{array}{l}\text { Chinese Elderly } \\
\text { Luncheon Club }\end{array}$ & $\begin{array}{l}\text { Chinese } \\
\text { Association }\end{array}$ & \begin{tabular}{|l|}
$60 /$ day \\
120/week \\
\end{tabular} & $\begin{array}{l}\text { 댄싱,마작,건강 } \\
\text { 상담,운동 }\end{array}$ \\
\hline & $\begin{array}{l}\text { Community of } \\
\text { Refugees from } \\
\text { Vietnam } \\
\end{array}$ & $\begin{array}{l}\text { Dockland } \\
\text { Settlement } \\
\text { Center } \\
\end{array}$ & $\begin{array}{l}\text { 50/day } \\
\text { 100/week }\end{array}$ & $\begin{array}{l}\text { 생활전반에 } \\
\text { 관한 도움상담 }\end{array}$ \\
\hline
\end{tabular}

친교그룹형의 런치클럽이 주를 이루고 있다. 첼트넘 지역의 런치클럽은 크게 4가지 유형으로 구분될 수 있는데 시니어센 터와 복지기관, 교회, 노인자치단체에서 운영하는 시설과 지 역의 기타시설에서 운영하는 형태이다. 대부분의 클럽은 고령 자를 대상으로 하고 있으며 일부는 70세 이상으로 나이를 제 한하고 있는 곳도 있으나, 대부분의 경우 나이제한 없이 운영 되고 있다. 일부는 청각장애자를 위한 서비스로 운영되고 있 다(Gloucestershire Rural Community Council, 2013).

운영형태도 도시지역에서는 주 $3 \sim 5$ 회 운영을 하고 있는 곳이 많지만, 농촌지역에서는 주1회 또는 월2회 정도의 런치 클럽은 물론 매일 서비스를 제공하는 런치클럽도 있어서, 고
령자들의 상태와 필요에 따라 다양하게 선택할 수 있는 기회 가 있다. 지역의 형편과 이용자의 필요에 따른 탄력적인 운영 형태는 기존 커뮤니티시설의 활용과 함께 경제적인 서비스의 전달방법이다.

비용도 지역의 여건에 따라 차등이 있으며, 교통서비스를 제공하는지 여부에 따라 추가비용을 부가하여 운영에 효율을 기하고 있다. 저소득 고령자만이 아니라 일반고령자에게도 이 러한 서비스공간의 이용은 매우 필요하다.

[Table 2] Lunch Clubs at Cheltenham, Gloucestershire

\begin{tabular}{|c|c|c|c|c|c|}
\hline $\begin{array}{l}\text { 구 } \\
\text { 분 }\end{array}$ & 시설명 & $\begin{array}{l}\text { 운영 및 } \\
\text { 부설형태 }\end{array}$ & $\begin{array}{l}\text { 이용 } \\
\text { 대상 }\end{array}$ & $\begin{array}{l}\text { 비용 } \\
(£) \\
\end{array}$ & 운영시간 \\
\hline \multirow{7}{*}{$\begin{array}{l}\text { 시 } \\
\text { 니 } \\
\text { 어 } \\
\text { 센 } \\
\text { 터 } \\
\text { 복 } \\
\text { 지 } \\
\text { 기 } \\
\text { 관 }\end{array}$} & $\begin{array}{l}\text { cheltenham } \\
\text { social club }\end{array}$ & $\begin{array}{l}\text { hearing } \\
\text { center }\end{array}$ & $\begin{array}{l}\text { hearing } \\
\text { impaired }\end{array}$ & 1.50 & - \\
\hline & \begin{tabular}{|l} 
Age UK \\
Gloucestershire \\
Day care \\
\end{tabular} & $\begin{array}{l}\text { daycare } \\
\text { center }\end{array}$ & $\begin{array}{l}\text { old } \\
\text { dementia }\end{array}$ & - & $\begin{array}{l}\text { mon, tu, } \\
\text { th }\end{array}$ \\
\hline & $\begin{array}{l}\text { Charlton Kings } \\
\text { Senior Citizens } \\
\end{array}$ & $\begin{array}{l}\text { community } \\
\text { center }\end{array}$ & retired & $\begin{array}{l}12 / y r \\
+1 / e a\end{array}$ & friday \\
\hline & $\begin{array}{l}\text { Senior Citizens } \\
\text { Welfare } \\
\text { Committee } \\
\end{array}$ & \begin{tabular}{|l|} 
day \\
center \\
at church \\
\end{tabular} & old & 7 & $\begin{array}{l}\text { tu-fri } \\
\text { 9-2pm }\end{array}$ \\
\hline & $\begin{array}{l}\text { Winchcombe Day } \\
\text { Center }\end{array}$ & $\begin{array}{l}\text { day } \\
\text { center }\end{array}$ & old & $\begin{array}{l}24 \\
\text { all } \\
\text { day } \\
\end{array}$ & $\begin{array}{l}\text { mon } \\
\text { wed } \\
\text { thursday } \\
\end{array}$ \\
\hline & \begin{tabular}{|l|} 
Gloucestershire \\
Deaf Lunch Club \\
\end{tabular} & $\begin{array}{l}\text { center for } \\
\text { deaf }\end{array}$ & \begin{tabular}{|l} 
BSL \\
users \\
\end{tabular} & 5.50 & $\begin{array}{l}\text { 1st } \\
\text { thursday }\end{array}$ \\
\hline & $\begin{array}{l}\text { Hawthorn } \\
\text { Luncheon Club }\end{array}$ & care home & $75+$ & free & tu \\
\hline \multirow{9}{*}{$\begin{array}{l}\text { 교 } \\
\text { 회 } \\
\text { 부 } \\
\text { 설 }\end{array}$} & $\begin{array}{l}\text { Highbury Lunch } \\
\text { Club }\end{array}$ & $\begin{array}{l}\text { community } \\
\text { cafe }\end{array}$ & all & 4 & $\begin{array}{l}\text { 2nd wed } \\
12 ; 15-1: 45\end{array}$ \\
\hline & $\begin{array}{l}\text { The Freindship } \\
\text { Club }\end{array}$ & $\begin{array}{l}\text { lunch40-60 } \\
\text { tea } 40\end{array}$ & $\begin{array}{l}\text { all } \\
60+ \\
\end{array}$ & $\begin{array}{l}3 \\
1.50 \\
\end{array}$ & \begin{tabular}{|l|}
2,4 wed \\
$12: 00-4: 00$ \\
\end{tabular} \\
\hline & $\begin{array}{l}\text { St. Matthew's } \\
\text { Thursday Club } \\
\end{array}$ & $\begin{array}{l}\text { church } \\
\text { hall } \\
\end{array}$ & all & \begin{tabular}{|l|}
2 \\
tea \\
\end{tabular} & $\begin{array}{l}\text { thursday } \\
\text { 2:00-4:30 } \\
\end{array}$ \\
\hline & \begin{tabular}{|l} 
St. Christopher's \\
Senior Club \\
\end{tabular} & $\begin{array}{l}\text { church } \\
\text { hall }\end{array}$ & $50+$ & 2 & wed \\
\hline & $\begin{array}{l}\text { Charlton Kings } \\
\text { Happy Circle } \\
\text { Club } \\
\end{array}$ & $\begin{array}{l}\text { church } \\
\text { hall }\end{array}$ & $50+$ & $\begin{array}{l}\text { 10/yr } \\
+1 / \text { ea }\end{array}$ & 3rd friday \\
\hline & \begin{tabular}{|l|} 
Bethesda \\
Methodist Church \\
Luncheon
\end{tabular} & $\begin{array}{l}\text { church } \\
\text { welcome } \\
\text { club 운영 }\end{array}$ & $70+$ & 2.50 & $\begin{array}{l}\text { tuesday } \\
12: 30\end{array}$ \\
\hline & $\begin{array}{l}\text { St. Mark's } \\
\text { Luncheon Club } \\
\end{array}$ & $\begin{array}{l}\text { community } \\
\text { center }\end{array}$ & $\begin{array}{l}\text { old } \\
\text { disabled }\end{array}$ & 3.50 & $\begin{array}{l}\text { tu-th } \\
9: 30 \\
\end{array}$ \\
\hline & $\begin{array}{l}\begin{array}{l}\text { Naunton Coffee } \\
\text { Shop }\end{array} \\
\end{array}$ & church cafe & all & 1 & $\begin{array}{l}\text { th } \\
10-12: 30 \\
\end{array}$ \\
\hline & TEMPO & church & old & free & wed \\
\hline \multirow{3}{*}{$\begin{array}{l}\text { 노 } \\
\text { 인 } \\
\text { 자 } \\
\text { 치 } \\
\text { 단 } \\
\text { 체 }\end{array}$} & \begin{tabular}{|l} 
Bishops Cleeve \\
Seniors Club
\end{tabular} & social club & $60+$ & $12 / y r$ & mon-sat \\
\hline & $\begin{array}{l}\text { Charlton Kings } \\
\text { Friendship Group }\end{array}$ & \begin{tabular}{|l|} 
transport \\
for \\
lunch \\
\end{tabular} & $\begin{array}{l}\text { old } \\
\text { disabled }\end{array}$ & free & everyday \\
\hline & \begin{tabular}{|l|} 
Badgeworth and \\
Redding \\
\end{tabular} & $\begin{array}{l}\text { community } \\
\text { center }\end{array}$ & retired & 2 & $\begin{array}{l}\text { 2nd, 4th } \\
\text { mon }\end{array}$ \\
\hline \multirow{4}{*}{$\begin{array}{l}\text { 기 } \\
\text { 타 }\end{array}$} & Chatter Box & $\begin{array}{l}\text { community } \\
\text { center }\end{array}$ & \begin{tabular}{|l|} 
retired \\
senior
\end{tabular} & free & - \\
\hline & $\begin{array}{l}\text { University of the } \\
\text { third Age }\end{array}$ & $\begin{array}{l}\text { private } \\
\text { house }\end{array}$ & retired & $12 / y r$ & - \\
\hline & \begin{tabular}{|l|} 
Prestbury \\
Memorial Trust \\
\end{tabular} & NPO & old & free & mon \\
\hline & Library Clubs & local library & $\begin{array}{l}\text { old } \\
\text { house } \\
\text { bound }\end{array}$ & free & - \\
\hline
\end{tabular}




\subsection{Elderly Food Senvice Environments in the U.S.}

미국의 고령자를 위한 커뮤니티서비스의 구성은 주로 식사 배달서비스, 시니어런치서비스, 수발자(care-givers)들을 위한 서비스, 자원봉사 네트워크서비스와 가정방문서비스와 더불 어 최근에는 커뮤니티키친 서비스를 운영하고 있다.

플로리다 주의 Brevard County는 인구가 540,000명 정도 의 지역으로, 이 지역의 커뮤니티서비스 단체인 Aging Matters는 1965년부터 이 지역 고령자들의 서비스를 담당하 고 있다. 1974년부터 식사배달서비스(Meals on Wheels) 프로 그램으로, 1992년부터는 커뮤니티키친을 통해서 하루 2000 명의 식사를 어린이와 고령자들에게 제공하고 있다. 시니어런 치(Seniors at Lunch)라는 프로그램은 영국의 런치클럽과 같 이 그룹 다이닝 프로그램으로, Brevard 지역의 15 개의 센터에 서 고령자들이 모여서 식사할 수 있는 공간을 제공하고 있다.

미국의 식사배달서비스는 대부분 영국의 런치클럽과 유사 한 모여서 식사하는 on-site meal program을 통하여 고령자 들이 식사할 수 있는 기회를 제공하고 있으며, 이러한 회합식 사(congregate meal) 공간은 점점 증가하고 있는 추세이다 (Linda Netterville et al, 2013).

뉴욕에 위치한 Encore Community Services는 맨하튼 중심 부 지역에 매일 더운 음식을 배달하고 있으며, 1 주에 2회 냉 동음식을 배달하고 있다. 또한 이 기관의 on-site meal program은 11 시와 12 시 30 분의 2 회로 나누어 하루 300 명 이 상의 점심식사를 제공하고 있다. 식사비용은 1.50 달러 정도의 기부를 받고 있으나, 기부를 하지 않아도 무료로 식사할 수 있 다(http://encorecommunityservice.org).

대부분의 커뮤니티센터는 커뮤니티키친을 중심으로 식사 배달과 회합식사를 병행해서 운영하는 형태로 운영되고 있다. 식사배달서비스의 프로그램을 통해서 메뉴 구성이나 위생상 태 등이 체계적으로 관리되고 있으며, 음식서비스(food service)가 필요한 사람들이 손쉽게 서비스에 접근할 수 있는 정보 제공이 이루어지고 있다. 식사공간도 단시간에 많은 식 사를 제공하는 것 보다는 적절한 인원의 할당을 통하여, 고령자 들이 보다 쾌적한 상태에서 식사할 수 있도록 배려하고 있다.

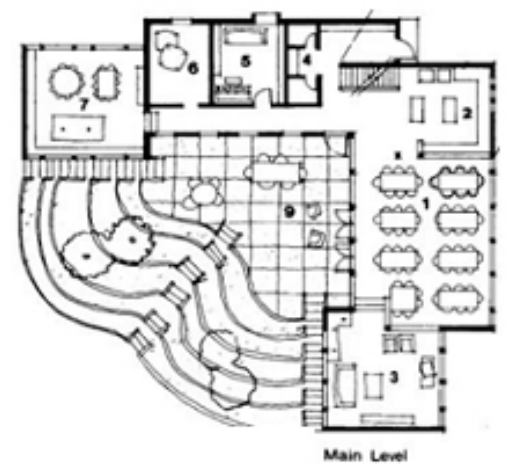

[Figure 3] Cohousing Common Space Design as a role of Community Kitchen (Cohousing-Designing the Urban Village :http://cohousing.webs.com/)

\subsection{Community Senior Salons in Japan}

일본에도 다양한 형태의 고령자 식사서비스센터를 운영하 고 있다. 일본 효고현(兵庫県) 고베시 타루미구(神戸市垂水区) 및 아카시시(明石市)에 위치한 메이마이 UR임대주택단지(明 舞團地, UR Meimai Housing Complex)는 건축된 지 30년 이 상 된 주거단지다. 이곳에서는 도시재생 프로그램의 일환으로 주택단지 내에 다양한 $\mathrm{NPO}$ (사회적 기업)가 참여하여 고령자 들을 위한 프로그램을 제공하고 있다.
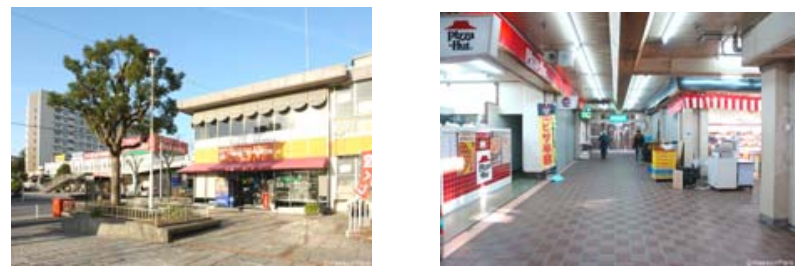

[Figure 4] Small Food Store for Senior Meal Delivery and In-room Dining in UR Meimai Housing Complex

$\mathrm{NPO}$ 단체가 상가 내에 작은 매장을 설치하여 식사준비가 어려운 고령자들에게 저렴한 비용을 받고 식사배달을 하고 있다. 고령자들이 언제나 들러서 저렴한 비용으로 식사를 하 거나 차를 마실 수 있는 동네 사랑방의 역할도 하고 있다. 또 한 고령자들을 위한 좋은 식재료들도 판매하여 멀리 떨어진 마트에 가기 어려운 고령자들을 위하여 건강에 좋은 먹거리 도 제공하고 있다.
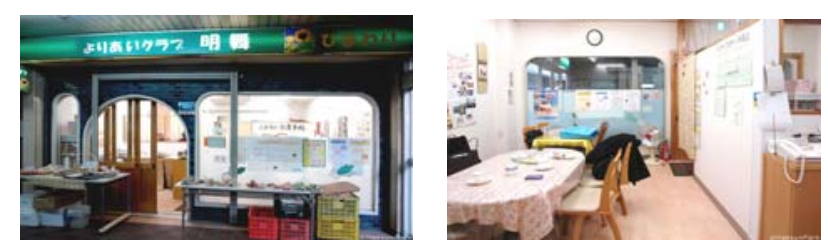

[Figure 5] Entrance and Interior of Senior Meal Service Space in UR Meimai Housing Complex

쿄토시 나카교구(京都市 中京区)에 위치한 소규모다기능 시설 아네야코지(姉小路, Aneyakouji)는 노인주간보호시설과 노인그룹홈으로 이루어진 시설인데, 1 층에는 도시락 배달과 동네 노인들의 사랑방 역할을 하는 살롱 공간을 두고 있다.
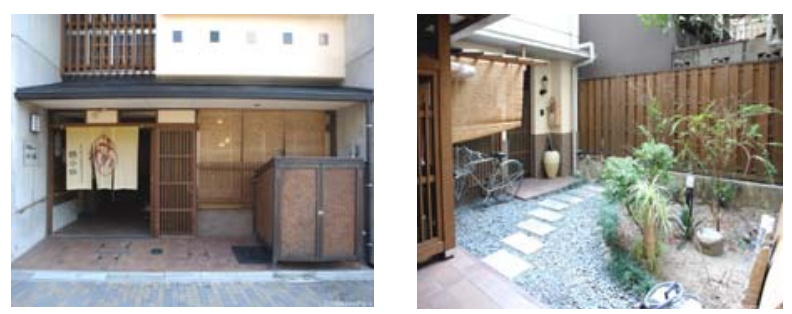

[Figure 6] Entrance and Garden of Multi-Purpose Senior Welfare Center Aneyakouji 

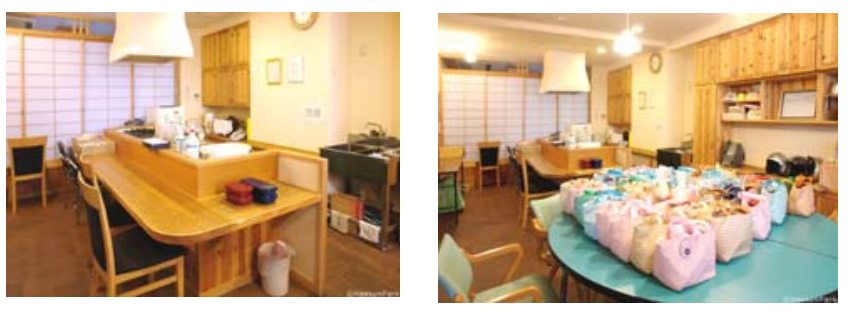

[Figure 7] Interior of Aneyakouji Senior Salon

\begin{tabular}{|c|c|}
\hline 고령자임대주택 & 고령자임대 주택 \\
\hline 그룹홈 & 그룹홈 \\
\hline 그룹홈 & 그룹홈 \\
\hline 거댁ㄱㄴ개하호소 & 데이서비스센터 \\
\hline (지역삭롭공공간) & 개인주택 \\
\hline
\end{tabular}

[Figure 8] Section of Aneyakouji

아네야코지의 시니어살롱은 주거단지 안에 위치한 메이마 이단지의 식당과는 달리 소규모 노인시설에 병설되어 있으며, 우리나라의 노인복지관의 식당보다 소규모로 지역 노인들이 편안하게 들려서 식사하고 쉬었다 갈 수 있는 공간이다.

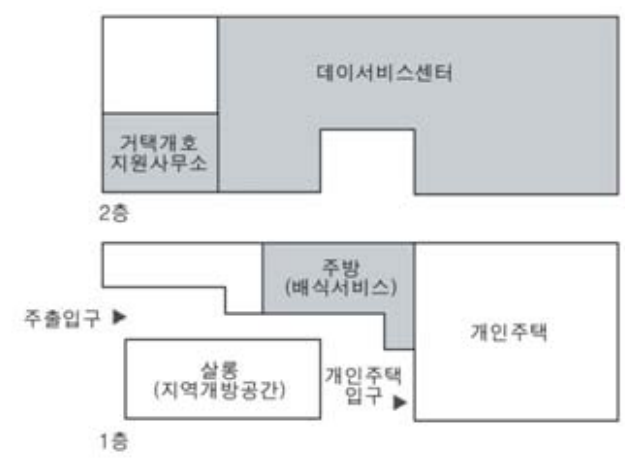

[Figure 9] Floor Plan of Aneyakouji

이 두 곳에서는 국내의 경로식당에서 제공되는 식사에 비 해 훨씬 더 가정식에 가까운 식사를 제공하고 있다. 또한 음식 을 담는 방법도 일반 도시락이 아니라 도시락 안에 접시가 들 어있는 형태로, 집에서 차린 식탁에서 먹는 것 같은 느낌을 가 질 수 있도록 배려하고 있다. 쿄토의 아네야코지 지역은 마을 만들기 프로젝트를 통하여 건축합의 협정지구로도 많이 알려 져 있는데, 고령자들에 대한 서비스도 지역밀착형으로 구성되 어 있다(Lee, Min Kyung et. al, 2007). 소규모의 식사공간과 가정식에 가까운 식사의 제공은 고령자들의 심리적인 요소를 배려한 공간 구성으로, 커뮤니티에 거주하는 고령자들의 정신 적인 면에서도 우울증 예방 등의 효과가 있다.
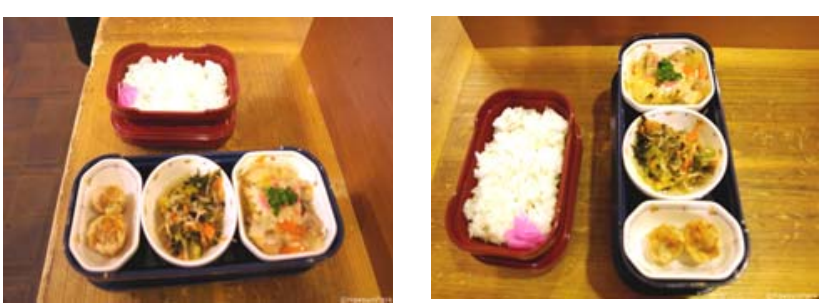

[Figure 10] Home-style Meal Service and Meal Delivery Container

본 연구에서 조사한 3 개국의 고령자를 위한 식사지원서비 스 센터의 경우 매우 다양한 형태의 공간에서 서비스가 이루 어지고 있다. 고령자들이 모여서 식사하고 활력을 얻을 수 있 도록 하는 장소가 노인복지센터 만이 아니라 종교시설, 자치 단체 등 다양한 형태의 커뮤니티 내 기존시설을 활용하고 있 다는 점에서 우리에게 시사하는 바가 크다. 또한 각 나라마다 공적인 공간만이 아니라 커뮤니티 내 활용 가능한 일반 식당 이나 아파트 단지의 상가 등 사적인 공간들을 활용할 수 있는 방법을 모색하고 있다. 따라서 설치 기준도 공간의 크기를 규 정하기 보다는 위생과 관련된 사항만을 관리하도록 기준을 설정하고 있다.

기존의 고령자들의 거주 지역으로부터 근접한 익숙한 건축 물 안에 사용가능한 공간들을 찾아내고 활용하는 것이, 고령 화 사회가 심화된 사회에서는 한정된 건축적 자원을 활용하 는 매우 중요한 요소가 되고 있다.

\section{Elderly lunch Service Spaces in Seoul}

국내 고령자를 위한 식사지원서비스의 현황을 파악하기 위 해 문헌조사와 함께 강남, 강북 각 1 개소와 소규모 경로식당 1 개소 등 지역과 규모가 다른 3 개소의 경로식당에 대해 현장 조사와 설문조사를 하였으며 이를 통하여 문제점을 파악하였 다. 경로식당 담당직원에 대한 심층 인터뷰(Focused Interview)가 21개 문항으로 구성된 설문으로 시행되었으며, 후속연구에 대한 방향을 설정하기 위하여 설문은 개방식 질 문 형식으로 이루어졌다. 설문내용은 이용자의 수, 저소득/일 반의 구분, 건강상태, 이용시간 등 이용자에 대한 내용, 경로 식당의 면적, 실내공간 구성 등 공간계획에 관한 내용, 그리고 비용, 교통편의서비스, 경로식당 내 안전사고 발생 등 운영에 관한 내용 등으로 조사하였다.

\subsection{Current Meal Service Programs of Elderly Center in Seoul}

국내의 커뮤니티 내 고령자에 대한 식사서비스는 주로 종 합사회복지관과 노인복지관을 중심으로 한 경로식당에서 담 당하고 있다. 서울시가 공식적으로 지원하고 있는 경로식당의 수는 현재 101개소로 조사되고 있는데, 비공식적으로 경로식 
당을 운영하고 있는 기관이 더 많은 것으로 알려져 있지만 체 계적인 조사·관리를 하지 못하고 있는 실정이다.

현재 경로식당 운영주체는 종합사회복지관에서 운영하는 것이 58 개소로 가장 많으며, 다음은 노인복지기관에서 운영 하는 것이 29 개소이다. 그 외에 종교기관과 기타시설에서 운 영하는 것이 3 개소로 매우 미미하나 종교기관에서 운영하고 있는 경로식당은 더 많을 것으로 예상된다. 그러나 단체 급식 시설로 허가를 받지 않은 경우가 많아 공식적인 수를 예측하 기 어렵다.

식사배달서비스도 노인복지센터 만이 아니라 많은 관련 단 체에서 시행하고 있지만 주로 저소득, 독거노인을 대상으로 하고 있다. 민간단체에 대한 서울시의 통계자료는 미비하며, 위생이나 영양에 대한 평가도 주로 자체적으로 이루어지고 있어 민간단체 운영에 대한 조사는 한계가 있으며, 차후에 조 사가 필요한 분야이다.

[Table 3] Senior Meal Service Facilities in Seoul (서울시 2013 저소득 어르신 경로식당 무료급식현황, http://opengov.seoul.go.kr/public/103116 을 참고로 구성)

\begin{tabular}{c|c|c|c|c|c}
\hline 구별 & $\begin{array}{c}\text { 종합사회 } \\
\text { 복지관 }\end{array}$ & $\begin{array}{c}\text { 노인복지 } \\
\text { 기놘 }\end{array}$ & $\begin{array}{c}\text { 종교 } \\
\text { 기관 }\end{array}$ & 기타 & 개소 \\
\hline 종 로 구 & 1 & 2 & - & 1 & 4 \\
\hline 중 구 & 2 & 2 & - & - & 4 \\
\hline 용 산 구 & - & 1 & - & - & 1 \\
\hline 성 동 구 & 3 & 1 & - & - & 4 \\
\hline 광 진 구 & 2 & 1 & 3 & - & 6 \\
\hline 동대문구 & 1 & 1 & 1 & 1 & 4 \\
\hline 중 랑 구 & 1 & 1 & 2 & - & 4 \\
\hline 성 북 구 & 4 & - & - & - & 4 \\
\hline 강 북 구 & 3 & - & 1 & 1 & 5 \\
\hline 도 봉 구 & 2 & 2 & - & - & 4 \\
\hline 노 원 구 & 4 & - & - & - & 4 \\
\hline 은 평 구 & 2 & 2 & - & - & 4 \\
\hline 서대문구 & 2 & 2 & - & - & 4 \\
\hline 마 포 구 & 1 & 3 & - & - & 4 \\
\hline 양 천 구 & 2 & 2 & - & - & 4 \\
\hline 강 서 구 & 3 & 1 & - & - & 4 \\
\hline 구 로 구 & 3 & 1 & - & - & 4 \\
\hline 금 천 구 & 2 & 2 & - & - & 4 \\
\hline 영등포구 & 2 & - & 2 & - & 4 \\
\hline 동 작 구 & 4 & - & - & - & 4 \\
\hline 관 악 구 & 4 & - & - & - & 4 \\
\hline 서 초 구 & 1 & 3 & - & - & 4 \\
\hline 강 남 구 & 2 & - & - & - & 3 \\
\hline 송 파 구 & 6 & - & - & - & 6 \\
\hline 강 동 구 & 1 & 2 & 1 & - & 4 \\
\hline 계 & 58 & 29 & 10 & 3 & 101 \\
\hline
\end{tabular}

지역적으로도 경로식당의 서비스 대상은 차이가 있는 것을 볼 수 있다. 강남에 위치한 송파노인복지관은 1 일 평균 200 300명의 고령자가 경로식당을 이용하고 있는데, 수급권 자는 무료이용이 가능하나 무료로 이용하는 사람은 현재 없 고 2,500원의 비용을 내고 식사하고 있다. 마포의 우리마포복 지관은 1 일 400 명의 이용자 중 100 명은 무료로 이용하고 있 고, 300 명은 비용을 지불하는 이용자로 조사되었다. 따라서 무료 위주의 운영이 아니라 일반 이용자의 비율이 훨씬 더 높 은 것을 알 수 있다.

\subsection{Interior Spaces of Korean Senior Meal Service Center}

국내 경로식당의 환경은 고령자들이 여유 있게 식사를 하 고 의미 있는 사회적 교류를 하기에는 아직 건축계획적인 배 려가 매우 부족하다고 판단된다. 노인복지관 경로식당의 평 균 이용인원은 1 일 200-400명이 가장 많은데, 식당 운영시간 은 1 시간 30 분 정도로 매우 짧고, 1 회 평균 식사할 수 있는 좌석 수는 70 90석으로 평균 3.5회전을 하는 것으로 조사되 었다. 그러할 경우 1 회전 당 식사시간은 20 분도 되지 않는 것 으로 고령자들이 충분한 여유를 가지고 식사할 수 없어 의미 있는 교류는 불가능하다(Yang, Ji Won et. al, 2008).

미국의 경우 2회전의 식사횟수 운영으로 고령자들의 식사 시간을 1 시간 이상 충분히 배려하고 있는 것에 비해, 국내 경 로식당은 급하게 식사를 해야 하는 경우가 많이 있다. 대부분 의 복지관에서는 고령자전용 식사공간이기 보다는 일반 회원 들과 직원, 방문자가 함께 식당을 이용하는 경우가 많아 더욱 혼잡하다.

국내 경로식당은 주로 지하1층 또는 최상층에 위치한 경우 가 대부분이고 옥외 공간과 연결되어 있는 경우는 많지 않다. 또한 국내 경로식당의 경우 소음이 매우 커서 식사에 집중할 수 없는 경우가 매우 많다. 또한 대부분의 국내 경로식당의 가 구는 매우 딱딱한 느낌의 의자를 사용하고 있으며, 한 테이블 의 좌석 수도 4 인 이하보다 많은 경우가 대부분이다.

국외의 고령자를 위한 식당공간의 디자인에서는 계획 시 탈시설화(De-institutionalizing)를 위해서 4인용보다 큰 대형 테이블 보다는 2 인 또는 4 인용 테이블을 사용하는 것이 바람 직하여 소규모 테이블 배치가 선호되고 있다. 또한 식사 중에 음악을 들을 수 있도록 하거나, 옥외공간(patios)이 제공되어 활용될 수 있다면 더욱 바람직하므로 식당공간과 옥외공간이 연결되도록 계획하고 있다(Susan Frampton et al., 2010: 194-198)

경로식당이라는 명칭도 고령자들에게 긍정적인 공간의 이 미지를 주고 있지 않아서 저소득 고령자만이 아니라 일반 고 령자들도 가고 싶은 공간의 이미지를 줄 수 있는 명칭에 대한 고민도 필요하다. 친근한 이미지의 소규모 가정적 공간에서 

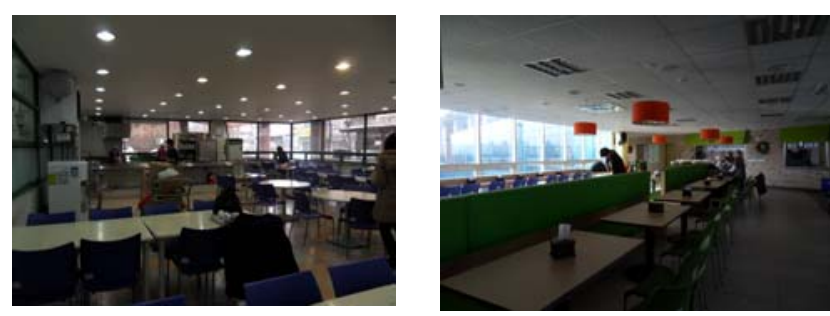

[Figure 11] Furniture Layout of Senior Dining Spaces of Elderly Welfare Centers in Seoul

고령자에 대한 식사지원서비스가 필요하며, 이러한 공간은 기 존의 복지관, 경로당, 종교시설 등 커뮤니티 내 기존공간의 리 노베이션을 통해 활용하는 방법을 찾는 것이 바람직하다.

인구대비 경로식당의 수를 영국과 비교하면 국내의 경우 너무 적은 개소에서 많은 인원을 담당하고 있어서, 커뮤니티 밀착형서비스를 제공하는 것은 어렵다고 판단된다. 조사대상 경로식당 중 2 곳은 차량서비스가 제공되고 있지 않고, 1 곳도 식사서비스 전용이 아닌 복지관 차량을 이용하고 있었다.

차량서비스가 제공되지 않는 경우에는 몸이 불편한 고령자 는 식사지원서비스 이용이 어렵고, 건강한 사람 위주의 서비 스가 되므로, 실제로 서비스가 필요한 고령자들에게 서비스가 제공되지 못하는 문제점도 예비조사를 통하여 밝혀졌다. 국외 의 사례에서도 가장 중요하게 다루어지고 있는 것이 서비스 의 근접성으로, 걸어갈 수 있는 거리에 설치하거나 교통서비 스의 제공이 필수적이다. 경로당과 같이 고령자들이 집에서 걸어갈 수 있는 거리에 소규모 런치클럽과 같은 공간을 형성 한다면 고령자들이 이용하기에 용이할 것이다.

국외의 런치클럽과 같은 역할을 담당하기 위해, 주거단지 근접한 곳에 커뮤니티키친을 설치하여, 커뮤니티 내 거주하고 있는 고령자들의 식사와 정서적인 안정에 도움을 줄 수 있는 방법을 제안하며 이에 대한 심층적인 연구가 필요하다. 커뮤 니티 내 소규모 고령자 식사지원서비스 공간의 설치 방법 및 공간 계획에 대해 심층적인 후속연구를 수행하고자 한다.

\section{Conclusion}

본 연구는 최근 선진 고령화국가에서 관심을 가지고 진행 하고 있는 고령자를 위한 식사지원서비스 공간에 대한 연구 를 통하여, 국내에서도 커뮤니티 내에 고령자들을 위한 식사 지원서비스 공간을 도입하는데 활용할 수 있는 방안에 대해 연구하였다. 연구의 결과는 다음과 같이 요약할 수 있다,

(1) 고령자를 위한 커뮤니티 내 식사서비스 환경은 고령자 의 지속적인 커뮤니티 거주를 위해서 매우 중요하며, 저소득 층 뿐 아니라 보다 폭넓게 모든 고령자들이 손쉽게 식사지원 을 받을 수 있어야 한다.
(2) 고령자 중 단독가구가 늘어남에 따라 항상 혼자 식사하 는 고령자들의 수가 증가하고 있으며, 이러한 상황은 고령자 의 우울증 등 정신적인 건강에 미치는 영향이 크므로, 커뮤니 티 내 고령자들이 모여서 식사할 수 있는 공간이 필요하다.

(3) 영국, 미국, 일본에서는 런치클럽 서비스를 통한 소규모 식사공간에서 고령자들이 정기적 혹은 비정기적으로 모여서 식사를 하면서 의미 있는 시간을 가질 수 있는 기회를 제공하 고 있다. 이러한 서비스를 운영하는 기관에서는 몸이 불편한 고령자들을 위한 식사배달서비스도 함께 담당하고 있는 경우 가 많다.

(4) 국내의 경로식당은 1 개소에서 지나치게 많은 인원을 담 당하고 있으며 시간적으로 여유 있는 식사를 할 수 없는 등 고령자에게는 바람직한 식사환경을 갖추고 있지 못하므로, 보 다 탈시설화된 식사환경에 대한 연구가 필요하다.

(5) 주거단지 내 혹은 그 근접한 곳에, 고령자들이 필요에 따라 모여서 식사하거나 식사배달을 받을 수 있고 식재료 구입 등에 대한 지원도 받을 수 있는 원스톱서비스가 필요 하다. 또한 이러한 서비스가 운영될 수 있는 '커뮤니티키친' 개념의 소규모공간이 설치되어 무료 또는 저렴한 비용으로 식사가 제공되는 것이 바람직하다. 커뮤니티키친에서는 요 리강습 등 다양한 프로그램을 통하여 젊은 세대 또는 아동 과의 세대교류의 기회를 제공할 수도 있어서 커뮤니티 거주 고령자들의 삶의 질을 높이는데 기여할 수 있다.

(6) 최근 많이 연구되고 있는 경로당 공간의 리노베이션 계 획 시 이러한 커뮤니티키친 개념의 도입을 고려할 필요가 있 으며, 이러한 공간이 지역의 고령자를 위한 식사지원서비스 및 런치클럽의 역할을 담당할 수 있을 것으로 기대된다.

Acknowledgements: This research was supported by Basic Science Research Program through the National Research Foundation of Korea(NRF) funded by the Ministry of Science, ICT \& Future Planning(NRF-2012R1A1A3015754)

\section{References}

Anne Dillon Roberts et al., 2004, Eating well for Older People: Practical and nutritional guidelines for food in residential and nursing homes and for community meals, 2nd Ed., The Caroline Walker Trust

Community Food and Health(Scotland), 2011, "meals and messages: a focus on food services for older people living in the community in scotland.", Community Food and Health(Scotland)

Community Food and Health(Scotland), 2011, "A bite and a Blether, Case Studies from Scotland's Lunch Clubs", Community Food and Health(Scotland)

Encore Community Services homepage, http://encore community services.org/ 
Gloucestershire Rural Community Council, 2013, "Luncheon and Social Clubs in the Cheltenham Area", Healthwatch Gloucestershire

Hwang, Ji Hye; Lee, Yeun Sook; Kang, Hye Yeon, 2010, "A Planning for Community Farming Garden Kitchen as Green Infra of Residential Welfare", Journal of the Korean Institute of Ecological Architecture and Environment V.10 n.2(19), pp. 15-18

Lee, Min Kyung; Weon, Se-Yong; Kim, Tai-Young, 2007, "Introduction and Practice of 'An Architectural Agreement' for Renewal of Residential District focused on Aneyakouji in the Center of Kyoto City", Korea Institute of Rural Architecture, V.9 n.2

Linda Netterville et al., 2013, "The New Congregate Meal Program: They are Growing, Partnering and Focusing on Health", N4A Conference Presentations, http://n4aagecomm. networkofcare4 elearning.org

London Borough of Tower Hamlets, 2013, "Directory of Lunch Club Services for Older People in Tower Hamlets" Lunch Clubs Providers' Forum

Meals on Wheels Association of America http://www. mowaa.org/ Susan Frampton et al., 2010, "De-institutionalizing the Dining Experience", Planetree and Picker Institute, Long- Term Care Improvement Guide, pp.194-198

Yang, Il-Sun; Jung, Hyun_Young, 2003, "Analyzing the Current Practice of the Home-Delivered Meal(HDM) Service Program for Homebound Elderly", Korean Journal of Community Nutrition V8. n5, pp.736-743

Yang, Ji Won; Lee, Bog-Hieu, 2008, "Survey on the Current Condition of Meal Service Environment and Kitchen Facilities in Cafeteria of the Korean Elderly Welfare Center", Chung Ang Journal of Human Ecology, V.28

全国コミュニティカフェ・ネットワーク（コミュニティカフェ全国連 絡会 ) profile, http://blog.canpan.info/com-cafe/profile, 2013.12.24

접수 : 2013년 12월 31일

1차 심사 완료 : 2014년 01월 17일

게재확정일자 : 2014년 01월 17일

3인 익명 심사 필

66 A Study on Food Service Environments for the Elderly in Community 